\title{
Prevalence of Peri-implant Diseases - Part 1
}

\section{Buttendorf AR ${ }^{1}$, Ferreira $\mathrm{CF}^{2}$, Oliveira de Souza JG ${ }^{1}$, Dalago $\mathrm{H}^{1}$ and Bianchini MA ${ }^{1}$}

${ }^{1}$ Department of Periodontology, Federal University of Santa Catarina, Florianópolis, SC, Brazil

${ }^{2}$ Department of Periodontology, University of Tennessee Health Sciences Center, College of Dentistry, Memphis, TN, USA

*Corresponding author: Cimara Fortes Ferreira, UTHSC College of Dentistry - Dunn Building, Suite S502, 875 Union Ave. Memphis TN 38163 , USA, Tel: 954 579 9545; Fax: 901448 6751; E-mail: cimarafortes@hotmail.com

Rec date: Apr 17, 2014; Acc date: May 16, 2014; Pub date: May 18, 2014

Copyright: (c) 2014 Buttendorf AR, et al. This is an open-access article distributed under the terms of the Creative Commons Attribution License, which permits unrestricted use, distribution, and reproduction in any medium, provided the original author and source are credited.

\section{Abstract}

Aim: Determine the prevalence of peri-implant diseases; mucositis and periodontitis, of patients from the Center of Studies of Continuing Education in Implant Dentistry of the Federal University of Santa Catarina. In addition to the extension of the disease, the proportion of affected implants was studied.

Materials and Methods: A cross-sectional study was carried out in 200 patients presenting 760 external-hexed cylindrical dental implant supported prosthesis with at least 1 year of loading time (range: 1-9 years). Probing depth, bleeding on probing and suppuration data was collected. Radiographs were required to evaluate supporting bone levels around implants.

Results: One hundred and thirty-nine (69\%) patients presented all healthy implants, $46(23 \%)$ patients presented peri-implant mucositis and $15(8 \%)$ presented peri-implantitis. The overall outcome was $547(72 \%)$ healthy implants, $161(21 \%)$ with peri-implant mucostitis and $62(7 \%)$ with peri-implantitis.

Conclusion: According to the results, it is concluded that the prevalence of peri-implant mucositis was $23 \%$ and peri-implantitis to $8 \%$.

\section{Clinical Relevance}

Scientific rationale for study: The prevalence of peri-implant diseases has not yet been presented with absolute values due to insufficient studies [1].

Principal findings: The peri-implant mucositis prevalence in this study was significantly lower than the results presented in the literature. However, peri-implantitis prevalence concurs and other time diverges with the literature.

Practical implications: Excessive force applied in the BOP exam could have resulted in false positive findings for the peri-implant diseases. Care is necessary to adequately diagnose the disease.

Keywords: Diagnostics; Infectious diseases; Peri-implant diseases; Peri-implantitis; Peri-implant mucositis; Prevalence

\section{Introduction}

Peri-implant mucositis is clinically described as the inflammation of the peri-implant mucosa without bone loss; being the most important clinical diagnosis the presence of bleeding on probing (BOP) [2]. Periimplantitis is associated with clinical characteristics of mucositis in combination with radiographic presence of bone loss $[3,4]$.

The prevalence of peri-implant diseases has not yet been presented with absolute values due to insufficient number of studies [1]. The absence of this information may be attributed to the lack of standardization of the scientific methodology; as well as, to the different definitions for peri-implant diseases [5-7]. It has been reported that peri-implant diseases are present in $28 \%$ to $56 \%$ [1] of individuals that present dental implants. Retrospective studies [8-15], with dental implant loaded for 5 or more years, revealed that periimplant diseases were a frequent finding; however, they showed very variable results. In 2008, the Council of the 6th European Workshop on Periodontology expressed the need for more studies to provide sufficient information in regards to the prevalence of peri-implant diseases [4].

This study aims to determine the prevalence of peri-implant diseases; mucositis and periodontitis, of patients from the Center of Continuing Education in Implant Dentistry (CEPID) of the Federal University of Santa Catarina (UFSC). In addition, the extension (the proportion of affected implants) of the disease was studied.

\section{Materials and Methods}

The present study was approved by the Human Ethics Committee of the Federal University of Santa Catarina and an informed consent was obtained from each participant.

\section{Sample selection}

Two hundred patients from the CEPID-UFSC database were randomly selected summing an amount of 760 external-hexed cylindrical implants presenting implant supported prosthesis placed for more than 1 year, from the period of 2001 to 2010. Of the 760 implants placed, $43 \%$ were mandibular teeth and $67 \%$ were maxillary. After initial adjustments of the suprastructures, the participants had not been recalled or maintained by the institute as part of a clinical routine, which was provided by the referring dentist. 


\section{Surgical protocol}

A consensus report from the 3rd European Workshop on Periodontology used the bone level at implant loading as the baseline [16]. All the implants were place with the platform placed at the level of the alveolar crest. When the implant was planned to be placed at a lower level then the existing bony ridge, the crest or the edentulous ridge was reduced. The platform-crest level surgical protocol used by the institution allowed an expected saucerization of $<2 \mathrm{~mm}$ for reaching the biological width [17]. Therefore, a bone loss of $\geq 2 \mathrm{~mm}$ was considered peri-implantitis $[14,18]$ when associated with presence of probing depth $(\mathrm{PD})>4 \mathrm{~mm}$ and/or bleeding/suppuration upon probing $[19,20]$.

\section{Data collection}

After each prosthesis was removed, the following data was collected:

BOP index: Presence or absence was registered after the introduction of $1 \mathrm{~mm}$ of the periodontal probe (PCV12PT Hu-Friedy Inc., Chicago, IL, USA) into the gingival sulcus with a gingival "sweep" movement [2]. Data was analyzed after removal of the periodontal probe and time elapsed for 30 seconds;

PD: PD measurements were collected on the mesial, mid-buccal, distal and the deepest site on the palatal/lingual, after calibration of the

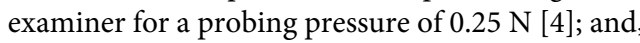

Suppuration: Visible presence or absence of suppuration was registered after probing the peri-implant sulcus.

\section{Radiographic analysis}

Bone level was measured around the dental implants using the parallel cone technique in order to obtain radiographic images (Kodak Insight film, Carestream, INC., New York, EUA) for analyses. The radiographs were digitalized by and image analysis program (Digimizer ${ }^{\oplus}$ version 3.7.0, Medical Software Brolkstraat, Belgium). The values were obtained by measuring the distance from the implant platform to the first radiographic bone contact on the mesial (MBL); and, on the distal (DBL). The measurements were made at baseline (T0) by only one calibrated examiner, different from the clinical examiner; and, repeated after 7 days (T7). The mean bone loss value obtained from both measurements (T0 and T7) was used as the final measurement of each site. For the final measurement for each implant, a mean bone loss value was established by adding the mesial mean with the distal mean values and dividing the sum by 2 .

\section{Group analysis and division}

The following criteria were used as the definition for the clinical and radiographic analyses. Peri-implant mucositis was considered when the probing depth was of $\leq 4 \mathrm{~mm}$ with presence of BOP around an implant presenting $<2 \mathrm{~mm}$ of bone loss. Data was compiled according to each implant and 4 sites (mesial, distal, mid-buccal and palatal/lingual). Peri-implantitis was defined when showing PD of $>4$ $\mathrm{mm}$, associated with BOP and/or suppuration, and bone loss $\geq 2 \mathrm{~mm}$ [6]. Bone loss was evaluated from the data compiled in 2 sites (mesial and distal) only, due to the inability to evaluate the mid-buccal and lingual/palatal implant sites in an $\mathrm{x}$-ray.

In the prevalence analyses, patients were divided into 3 groups: 1 ) Healthy; 2) presenting mucositis (at least 1 implant with mucositis); and, 3) presenting peri-implantitis (at least 1 implant with peri- implantitis). While analyzing the results when all the implants were taken into consideration, they were divided into 4 groups; implants without bleeding and with less than $2 \mathrm{~mm}$ of bone loss; implants without bleeding and with $\geq 2 \mathrm{~mm}$ of bone loss; implants with mucositis; and, implants with peri-implantitis. The division of the healthy implants (without bleeding) into 2 groups aimed to optimize the evaluation of the subjects presenting peri-implant bone loss of $\geq 2$ $\mathrm{mm}$, even in the absence of bleeding, which may suggest a history of peri-implantitis [7].

\section{Statistical analyses}

All data were compiled and compared between groups. The extraexaminer reproducibility of the MBL and DBL measurements was tested with the intra-class correction coefficient (ICC).

Binary logistic regression analysis was applied for the comparison amongst the groups of the presence of mucositis and peri-implantitis. The assumed confidence interval was of 95\%. The Microsoft Excel (Microsoft Office XP) and Statistical Package for Social Science (SPSS) programs for Windows (version 13.0) were used for value data tab and data analyses. Statistical significance was considered significant when $\mathrm{P}$ was less than 0.05 .

\section{Results}

The sample size was composed of 200 patients that summed a total amount of 760 dental implants. Regarding the time the implant supported prostheses were in function, 162 patients (611 implants) had the prostheses for up to 5 years, and 38 patients ( 149 implants) for more than 5 years. The mean time interval with the prostheses in function was of 4.02 years (standard deviation of 1.67 years). The patient age ranged from 21 to 86 years, with an average of 50.6 years (standard deviation of 11.22). Gender was distributed as $64 \%$ females. Sample details are presented in Table 1.

\begin{tabular}{|l|l|l|}
\hline \multirow{2}{*}{ Variables } & Sample & Implants placed \\
\cline { 2 - 3 } & $\mathbf{n}(\%)$ & $\mathbf{n}(\%)$ \\
\hline Sex $(\mathbf{n}=\mathbf{2 0 0})$ & & \\
\hline Male & $71(34.7)$ & $304(40.0)$ \\
\hline Age (years) $(\mathbf{n = 2 0 0 )}$ & $129(64.3)$ & $456(60.0)$ \\
\hline $19-39$ & & \\
\hline $40-49$ & $32(16.0)$ & $88(11.6)$ \\
\hline $50-59$ & $66(33.3)$ & $196(25.9)$ \\
\hline 60 or more & $61(30.5)$ & $298(39.3)$ \\
\hline Scholarity (n=200) & $41(20.2)$ & $177(23.2)$ \\
\hline Up to 8th grade & & \\
\hline Up to 12th grade & $36(17.1)$ & $125(16.2)$ \\
\hline College & $85(43.0)$ & $348(46.0)$ \\
\hline TOTAL & $79(39.9)$ & $287(37.8)$ \\
\hline
\end{tabular}

Table 1: Description of the samples regarding sex, age and scholarity 
Page 3 of 4

From a total of 139 (69\%) patients presenting all implants healthy, $46(23 \%)$ patients presented at least 1 implant with peri-implant mucositis and $15(8 \%)$ patients with at least 1 implant with periimplantitis. Table 2 shows the distribution of patients according to sex and the prevalence category of the peri-implant diseases.

\begin{tabular}{|l|l|}
\hline Groups $^{*}$ & Total \\
\hline 1 & 139 \\
\hline 2 & 46 \\
\hline 3 & 15 \\
\hline Total & 200 \\
\hline $\begin{array}{l}\text { *1) Healthy patients; } \\
\text { 2) Patients with peri-implant mucositis; } \\
\text { 3) Patients with peri-implantitis }\end{array}$ \\
\hline
\end{tabular}

Table 2: Distribution of patients according to sex and prevalence category for peri-implant diseases

Table 3 shows the detailed results of the 760 implants distributed in the 4 groups according to the prevalence of the peri-implant diseases.

\begin{tabular}{|l|l|l|}
\hline Groups $^{*}$ & Number of implants & Percentage \\
\hline 1 & 418 & $55 \%$ \\
\hline 2 & 129 & $17 \%$ \\
\hline 3 & 161 & $21 \%$ \\
\hline 4 & 52 & $7 \%$ \\
\hline Total & 760 & $100 \%$ \\
\hline
\end{tabular}

*1) Healthy implants without bone loss; 2) Healthy implants with bone loss and without BOP; 3) Implants with peri-implant mucositis; 4) Implants with periimplantitis

Table 3: Distribution of implants according to the prevalence category of the peri-implant diseases

\section{Discussion}

Studies show a considerable variation in the prevalence of periimplant diseases. However, Pjetursson et al. [21] has presented similar results to the present study. They conducted a systematic review which indicated an incidence of $8.6 \%$ for peri-implantitis for dental implants in function for more than 5 years. Another similar analysis was shown by Berglundh et al. [22], Ferreira et al. [23] and Rinke et al. [24], when the prevalence of peri-implantitis was of $6.4 \%, 8,9 \%$ and $11,2 \%$, respectively.

The prevalence of peri-implantitis in the present study differ from the ones presented by the systematic review conducted by Zitzmann and Berglundh [1], where $80 \%$ of the subjects showed peri-implant mucositis and $28 \%-56 \%$ presented peri-implantitis. Our results also differ from those presented by Koldsland et al. [6] and Mir-Mari et al. [7]. It can be assumed that this higher percentage could be attributed to the time that the implants were in function, which in this review was a minimum of 5 years. Therefore, even after separating the data of the 38 patients with dental implants in function for more than 5 years, the results still show great discrepancy. Karoussis et al. [25] and Rinke et al. [24] showed that studies evaluating dental implants in function for less than 5 to 10 years may not reproduce the differences in the susceptibility to bone loss due to the fact that peri-implant diseases can take years to develop [26].

Variations in the factors and methods of analyses may contribute to the discrepant results shown in the literature. As already described [1], the diverse methods of analysis (participants/dental implants) was a determinant factor for the exclusion of the majority of the 683 studies reviewed. Other exclusion factors of this review are the clinical and radiographic criteria used for the identification of peri-implant diseases, which make it impractical to compare results from different studies. In regards to this criteria, 2 problems are evident; the absence of fundamental criterions, and the lack of standardization. An example of this lack of criterion was that in one study there was absence of clinical data, as: BOP, which is fundamental for diagnosis of the presence of a peri-implant disease.

Dental implant loss may be due to multiple episodes of peri-implant infections [27] and; therefore, in some instances absence of clinical signs may mask the previous disease. Based in this premise, it may be suggested to add the data from the group presenting implants with bone loss of $\geq 2 \mathrm{~mm}$ and without BOP of the present study, to the date from the group presenting peri-implantitis. This would indicate a result similar to the one presented by Ellegaard et al. [28] and Karoussis et al. [25].

The greatest discrepancies of the results were found in the prevalence of peri-implant mucositis. The prevalence of the disease in the present study was significantly lower than the literature reviewed. A possible factor for this discrepancy could be the force used to perform the BOP exam. The standardization of the probing pressure was a determinant factor for the correct diagnosis of the peri-implant diseases and this factor should be considered while validating the comparison amongst results. Some studies show that the peri-implant mucosa could be more sensitive to probing, which would account for a higher percentage of BOP in these tissues when compared to teeth [29-30]. In the present study, the selection and calibration of the examiners demonstrates the importance of applying only the necessary force for measuring the clinical inflammation accurately. From a total of 14 possible trained examiners, only 2 presented a tolerant limit of applied force variation. Twelve examiners demonstrated force limitations of $50 \mathrm{~N}$, even after calibration; therefore, they were not used in this study. Radiological studies show that the tip of the periodontal probe was in close proximity to the peri-implant marginal bone when the probing forces were of $0.5 \mathrm{~N}$ or more [31]. Ericsson and Lindhe [32] also showed, in an experimental study, that in the healthy peri-implant mucosa, a probing force of $0.5 \mathrm{~N}$ resulted in the tip of the probe passing through the connective tissue and being in close proximity to the marginal bone. It is possible that the discrepancy of the results, regarding specifically peri-implant mucositis, could be due to this factor. Some reviewed studies did not mention the probing force applied or the calibration phase as part of the methodology. The authors of the present study suggest the use of electronic periodontal probes to standardize clinical measurements.

The total number of existing cases in a determined population indicates the prevalence of a disease. Therefore, the prevalence of a disease should be determined by the number of individuals and not the number of individual dental implants [1]. Finally, there is a need for describing the extension of the diseases; that is, in regards to the amount and the severity (quantity of bone loss) of dental implants affected in each individual. The ability of obtaining data in a more 
organized manner will allow for the prevalence and severity of periimplant diseases to be consequently conclusive, as already suggested by Heitz-Mayfield [26]. Special attention should be given to the standardization of the different criteria applied, as: follow-up time intervals and the criteria used to differentiate health from diseased sites.

According to the results obtained from the present study, it was concluded that the prevalence of peri-implant mucositis was $23 \%$ and for peri-implantitis was $8 \%$ of the studied group for implants placed for more than 1 year in function.

\section{References}

1. Zitzmann NU, Berglundh T (2008) Definition and prevalence of periimplant diseases. J Clin Periodontol 35: 286-291.

2. Ainamo J, Bay I (1975) Problems and proposals for recording gingivitis and plaque. Int Dent J 25: 229-235.

3. Albrektsson T, Isidor F (1994) Consensus report of session IV. Quintessence, England.

4. Lindhe J, Meyle J (2008) Peri-implant diseases: Consensus Report of the Sixth European Workshop on Periodontology. J Clin Periodontol 35: 282-285.

5. Savage A, Eaton KA, Moles DR, Needleman I (2009) A systematic review of definitions of periodontitis and methods that have been used to identify this disease. J Clin Periodontol 36: 458-467.

6. Koldsland OC, Scheie AA, Aass AM (2010) Prevalence of peri-implantitis related to severity of the disease with different degrees of bone loss. J Periodontol 81: 231-238.

7. Mir-Mari J, Mir-Orfila P, Figueiredo R, Valmaseda-Castellón E, GayEscoda C (2012) Prevalence of peri-implant diseases. A cross-sectional study based on a private practice environment. J Clin Periodontol 39: 490-494.

8. Scheller H, Urgell JP, Kultje C, Klineberg I, Goldberg PV, et al. (1998) A 5-year multicenter study on implant-supported single crown restorations. Int J Oral Maxillofac Implants 13: 212-218.

9. Fransson C, Wennström J, Berglundh T (2008) Clinical characteristics at implants with a history of progressive bone loss. Clin Oral Implants Res 19: 142-147.

10. Polizzi G, Grunder U, Goene R, Hatano N, Henry P, et al. (2000) Immediate and delayed implant placement into extraction sockets: a 5year report. Clin Implant Dent Relat Res 2: 93-99.

11. Baelum V, Ellegaard B (2004) Implant survival in periodontally compromised patients. J Periodontol 75: 1404-1412.

12. Karoussis IK, Brägger U, Salvi GE, Bürgin W, Lang NP (2004) Effect of implant design on survival and success rates of titanium oral implants: a 10-year prospective cohort study of the ITI Dental Implant System. Clin Oral Implants Res 15: 8-17.

13. Brägger U, Karoussis I, Persson R, Pjetursson B, Salvi G, et al. (2005) Technical and biological complications/failures with single crowns and fixed partial dentures on implants: a 10-year prospective cohort study. Clin Oral Implants Res 16: 326-334.

14. Roos-Jansåker AM, Lindahl C, Renvert H, Renvert S (2006) Nine to fourteen year follow-up of implant treatment. Part II: presence of periimplant lesions. J Clin Periodontol 33: 290-295.
15. Renvert S, Roos-Jansåker AM, Lindahl C, Renvert H, Persson RG (2007) Infection at titanium implants with or without a clinical diagnosis of inflammation. Clin Oral Implants Res 18: 509-516.

16. Wennström JL, Palmer RM (1999) Consensus report of session C. Quintessenz Verlags, Berlin.

17. Albrektsson T, Brånemark PI, Hansson HA, Lindström J (1981) Osseointegrated titanium implants: requirements for ensuring a longlasting, direct bone to implant anchorage in man. Acta Orthopaedica Scandinavica 52: 155-170.

18. Fransson C, Lekholm U, Jemt T, Berglundh, T (2005) Prevalence of subjects with progressive bone loss at implants. Clin Oral Implants Res 16: 440-446.

19. Fransson C, Tomasi C, Pikner SS, Gröndahl K, Wennström JL, et al. (2010) Severity and pattern of peri-implantitis-associated bone loss. J Clin Periodontol 37: 442-448.

20. Roos-Jansaker AM, Lindahl C, Renvert H, Renvert S (2006) Nine- to fourteen year follow-up of implant treatment. Part I: implant loss and associations to various factors. J Clin Periodontol 33: 283-289.

21. Pjetursson BE, Tan K, Lang NP, Brägger U, Egger M, et al. (2004) A systematic review of the survival and complication rates of fixed partial dentures (FPDs) after an observation period of at least 5 years. Clin Oral Implants Res 15: 625-642.

22. Berglundh T, Persson L, Klinge B (2002) A systematic review of the incidence of biological and technical complications in implant dentistry reported in prospective longitudinal studies of at least 5 years. J Clin Periodontol 29: 232-233.

23. Ferreira SD, Silva GLM, Cortelli JR, Costa JE, Costa FO (2006) Prevalence and risk variables for peri-implant disease in Brazilian subjects. J Clin Periodontol 33: 929-935.

24. Rinke S, Ohl S, Ziebolz D, Lange K, Eickholz P (2011) Prevalence of periimplant disease in partially edentulous patients: a practice-based cross-sectional study. Clin Oral Implants Res 22: 826-833.

25. Karoussis IK, Salvi GE, Heitz-Mayfield LJ, Brägger U, Hämmerle CH, et al. (2003) Long-term implant prognosis in patients with and without a history of chronic periodontitis: a 10-year prospective cohort study of the ITI Dental Implant System. Clin Oral Implants Res 14: 329-339.

26. Heitz-Mayfield LJ (2008) Peri-implant diseases: diagnosis and risk indicators. J Clin Periodontol 35: 292-304.

27. Schou S, Holmstrup P, Hjørting-Hansen E, Lang NP (1992) Plaqueinduced marginal tissue reactions of osseointegrated oral implants: a review of the literature. Clin Oral Implants Res 3: 149-161.

28. Ellegaard B, Baelum V, Karring $T$ (1997) Implant therapy in periodontally compromised patients. Clin Oral Implants Res 8: 180-188.

29. Jepsen S, Rühling A, Jepsen K, Ohlenbusch B, Albers HK (1996) Progressive peri-implantitis. Incidence and prediction of peri-implant attachment loss. Clin Oral Implants Res 7: 133-142.

30. Lekholm U, Adell R, Lindhe J, Brånemark PI, Eriksson B, et al. (1986) Marginal tissue reactions at osseointegrated titanium fixtures. (II) A cross-sectional retrospective study. Int J Oral Maxillofac Surg 15: 53-61.

31. Mombelli A, Mühle T, Brägger U, Lang NP, Bürgin WB (1997) Comparison of periodontal and peri-implant probing by depth-force pattern analysis. Clinical Oral Implants Research 8: 448-454.

32. Ericsson I, Lindhe J (1993) Probing depth at implants and teeth. An experimental study in the dog. J Clin Periodontol 20: 623-627. 